\section{Cordeiro R. Trabalho, violência e morte: miséria da existência humana. Curitiba: Appris; 2018}

\author{
Élida Azevedo Hennington \\ (https://orcid.org/0000-0001-5280-8827) ${ }^{1}$ \\ ${ }^{1}$ Escola Nacional de Saúde Pública, Fiocruz. Rio de \\ Janeiro RJ Brasil.
}

O livro do epidemiologista Ricardo Cordeiro, prefaciado pela pesquisadora Cecília Minayo, aborda a mortalidade por acidentes de trabalho (AT) e seu imbricamento com a violência urbana a partir de triangulação de métodos qualitativo e quantitativo. Militante e pesquisador da área de Saúde Coletiva, Cordeiro tem se dedicado há 30 anos a investigar as relações entre saúde e trabalho e, atualmente, coordena o laboratório de Análise Espacial de Dados Epidemiológicos da Unicamp. O livro é baseado em pesquisa que buscou analisar mortes relacionadas ao trabalho na cidade de Campinas, SP, no ano de 2015. Neste ano foram identificados 82 acidentes de trabalho fatais de residentes no município paulista, um acidente a cada quatro dias, 10 acidentes fatais para cada 100 mil moradores em idade economicamente ativa, o que já demonstra a urgência e importância da abordagem do tema.

Os acidentes de trabalho são agravos notoriamente subnotificados no Brasil e, mesmo assim, estima-se a ocorrência de um AT a cada 48 segundos e uma morte a cada 3 horas e 38 minutos $^{1}$. Além do subregistro, muitos eventos não são reconhecidos como AT. Do total de óbitos por AT em Campinas, 35 mortes foram resultantes de acidentes de trânsito que vitimaram pessoas a caminho do trabalho ou no retorno ao lar. O restante, outros 47 acidentes fatais decorrentes de homicídios, suicídios, quedas, agressões, desabamentos e outras causas, foram descritos e compuseram os demais capítulos que estruturam o livro. Cada um destes capítulos conta a história e circunstâncias da morte construídas a partir de relatos de familiares, amigos, vizinhos e colegas dos trabalhadores falecidos, complementados por informações das declarações de óbito, boletins de ocorrência, laudos do Instituto Médico-Legal e do noticiário em geral.

O livro inicia com a descrição da necropsia de um trabalhador, Josué, personagem central do primeiro caso retratado e que, segundo o autor, motivou-o a querer conhecer sua história pessoal e a estudar os óbitos por AT para além da frieza dos números, a partir do relato dos vivos. A pesquisa tenta então reconstituir pelo menos parte da história desses trabalhadores "que encontraram a morte enquanto lutavam pela vida"2. A obra vai chegando ao fim com um capítulo sobre a análise dos óbitos do ponto de vista epidemiológico e a distribuição espacial das mortes e do risco de morrer de trabalhadores no município, finalizando com a continuação da primeira história narrada que tem o sugestivo título de "Amor bandido", a história de Josué. Um homem negro de 30 anos, motorista de ônibus urbano e que tinha tatuado no braço a seguinte frase: "Te amo, Juliana".

Com muita sensibilidade e de forma pouco usual nos meios acadêmicos, o autor descreve esta e outras histórias à maneira de crônicas curtas, "em leve narrativa de assuntos tão pesados”, segundo $\mathrm{Minayo}^{3}$, oferecendo ao leitor um panorama triste e pungente da realidade laboral na terceira cidade mais populosa do estado de São Paulo e que, certamente, poderia ser extrapolado para a maioria dos centros urbanos brasileiros. Os personagens principais são, em geral, homens adultos jovens, pobres, de baixa escolaridade e pouca qualificação profissional, precarizados e moradores da periferia, lugar onde "mais se mata e mais se morre"3. O livro nos convoca a refletir sobre as transformações no mundo do trabalho e seus impactos na forma de viver e morrer de trabalhadores brasileiros como o crescimento do setor de serviços, a ampliação dos ambientes de trabalho para além do chão da fábrica ou dos escritórios fechados e a ocupação dos espaços da rua, o crescimento do desemprego e da informalidade e a exposição a "novos riscos" como a violência urbana, especialmente a criminalidade e os acidentes de trânsito. Os AT seguem apresentados em ordem cronológica de ocorrência e por mais que algumas situações pareçam inverossímeis, o que surpreende é que, conforme adverte o autor logo nas primeiras páginas, exceto os nomes próprios das pessoas e dos lugares, tudo era verdade. Chamam atenção os cenários de extrema pobreza e as motivações socioculturais para muitas mortes de trabalhadores que nossa sociedade armada, machista e patriarcal sustenta e fortalece como crimes passionais e de honra, brigas e uso problemático de álcool e drogas. Histórias retratadas de amor e desamor como a de Josué e Juliana e que relembram o poema de Drummond ${ }^{4}$, "A quadrilha", e muitas outras apresentadas ao longo do livro. Narrativas que mobilizam e comovem pela saudade, apatia, revolta ou resignação como os interlocutores encaram a morte do ente querido e que, apesar do final sempre trágico, às vezes até nos levam a sorrir, seja pelo inusitado da situação, seja pela poesia e singeleza que emerge mesmo em meio à precariedade daquelas vidas.

A narrativa imposta por Ricardo Cordeiro nos faz por um momento esquecer que se trata não de um livro de crônicas urbanas, mas de resultados de pesquisa científica. Sua forma peculiar de contar histórias remete a consagrados escritores brasileiros,

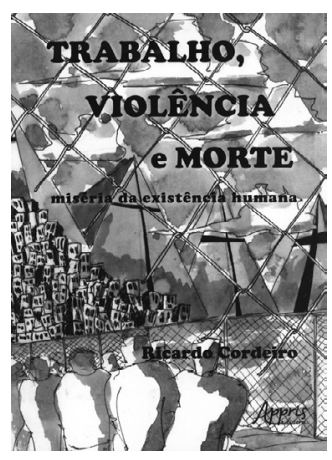


como Nelson Rodrigues e Rubem Fonseca, pela fina ironia, às vezes, sarcasmo que já se anuncia no título de cada capítulo, pela descrição detalhada e mórbida das situações que explicavam ou cercaram as mortes e a tentativa, aparentemente proposital, de chocar o leitor com a crueza do cotidiano de pessoas que perambulam pela vida em busca da sobrevivência numa sociedade violenta. Ao reconstituir os últimos momentos da vida de trabalhadores brasileiros, o autor nos coloca frente a frente com histórias como a da prostituta Tamara, 22 anos, que morreu esfaqueada pelo cliente que não concordou com o preço do programa, ou do motoboy Murilo, 19 anos, trabalhador informal, que perdeu a vida atingido por um ônibus quando fugia do engarrafamento, ou de Josenildo, 47 anos, caminhoneiro, trabalhador autônomo que morreu preso às ferragens e que segundo sua mãe sempre foi um homem "muito trabalhador e não merecia morrer desse jeito"2, ou de Claudinei, instalador de outdoor, um dos poucos com carteira assinada deste universo de trabalhadores, que faleceu esmagado pela estrutura que tentava montar. Ficamos sabendo que, felizmente, sua esposa conseguiu receber a pensão devida, porém não saía de casa, emagreceu 20 quilos e continuava chorando a morte do marido. E ainda três casos de suicídio: o de um pintor industrial com histórico de exposição a solventes, o de um jardineiro exposto a agrotóxicos e o de um pequeno empresário ameaçado por credores que se matou trancado no escritório. Para Dejours e Bègue $^{5}$ o suicídio no local de trabalho é sempre uma mensagem extremamente brutal dirigida à comunidade de trabalho, aos colegas, ao chefe, aos subalternos, à empresa, uma mensagem que precisa ser decodificada e não há dúvida de que o trabalho está posto em foco. Para os autores, o suicídio muitas vezes se associa à destruição de elos sociais, ao fim das estratégias de defesa e das redes de solidariedade no trabalho e fora dele.

Ao final da leitura de tantas histórias tristes, voltamos à realidade e pensamos: não, não era ficção. São histórias reais de pessoas que morreram enquanto lutavam pela sobrevivência. São histórias de trabalhadores que morrem aqui e acolá, trabalhadores precarizados, explorados, subempregados, desempregados e alguns que, embora inseridos no setor formal da economia, morreram de causas plenamente evitáveis, num país onde prevenção é sinônimo de gastos e de custos. Trabalhadores invisibilizados. Do total de
AT identificados pelo estudo, apenas 10 foram detectados pelo Sistema de Informações de Agravos de Notificação e somente 5 pelo Sistema de Informação de Mortalidade.

$\mathrm{O}$ autor destaca que há muito se discute a necessidade de mudanças no sistema de notificação e registro de AT, mas este tema continua como um dos grandes desafios para a Saúde do Trabalhador, bem como as estratégias para prevenir acidentes, proteger a saúde dos trabalhadores e resguardar seus direitos. São histórias que refletem as desigualdades e a injustiça do meio social no qual vivemos. Mas apesar dos problemas e da dureza do tema, o livro ao dar voz e visibilidade às mortes a partir do relato dos que sobreviveram para contar, acidentes que de outro modo passariam ocultados ou desapercebidos, dá também pistas para futuras intervenções e termina trazendo a esperança de que possamos mudar o curso da história, que o ofício de pesquisador e sua missão de produzir conhecimento possam contribuir para a construção de uma sociedade mais justa e solidária com os trabalhadores que ajudam a construir com sua labuta diária este país.

Esta resenha termina trazendo novamente Drummond ${ }^{6}$ num dos momentos mais emocionantes do livro, a história de Jerônimo, o cuidador de cavalos, ex jóquei, que morreu com dois coices na cabeça. Um trabalhador representado e imortalizado pelo poema "A morte a cavalo" emoldurado num quadro pendurado na sala de estar pela viúva após a morte do marido: "A cavalo de galope depois de levar meus pais a morte sem prazo ou norte vai levando meus amores".

\section{Referências}

1. Ministério Público do Trabalho. Smartlab - Observatório Digital de Saúde e Segurança no Trabalho. [acessado 2018 Nov 15]. Disponível em: https://observatoriosst. mpt.mp.br/.

2. Cordeiro R. Trabalho, violência e morte: miséria da existência humana. Curitiba: Appris; 2018.

3. Minayo MCS. Prefácio: O abraço fatal que une violência com acidentes no trabalho. In: Cordeiro R, organizador. Trabalho, violência e morte: miséria da existência humana. Curitiba:Appris, 2018.

4. Andrade CD. Alguma poesia. São Paulo: Companhia das Letras; 2013.

5. Dejours C, Bègue F. Suicídio e trabalho: o que fazer? Sobradinho: Paralelo 15; 2010.

6. Andrade CD. A morte a cavalo. A paixão medida. São Paulo: Companhia das Letras; 2014. 